\title{
EDUCAÇÃO, PSICASTENIA E INTELECTUALIDADE
}

\author{
Leandro Petarnella * \\ Maria Lucia de Amorim Soares ${ }^{* *}$ \\ Eliete Jussara Nogueira **
}

\begin{abstract}
RESUMO
Partindo do questionamento das implicações tecnológicas em sala de aula, este artigo busca desvelar as maneiras pelas quais podem ser realizadas as práticas docentes frente ao excesso informacional. Este último, matriz constituinte do estado psicastênico hodierno. Para tanto, utiliza-se dos trabalhos de Vilém Flusser, Gilles Deleuze e Josef Esquirol, como arcabouço teórico, para o entendimento de que frente à psicastenia socialmente generalizada, trabalhar a dúvida enquanto condição do desenvolvimento da contemplação e da intelectualidade se faz como o desafio da educação formal.
\end{abstract}

Palavras-chave: Dúvida. Educação. Intelectualidade. Psicastenia. Práticas pedagógicas.

\begin{abstract}
Questioning the technological implications in the classroom, this article seeks to uncover the ways in which pedagogic practices can be performed forward to excess informational. This latter, constituent of current psychasthenic condition. To this end, part of the work of Flusser, Gilles Deleuze and Josef Esquirol to the understanding that the front of
\end{abstract}

\footnotetext{
* Doutor em Educação pela Universidade de Sorocaba (2011). Professor do Departamento de Ciências Gerenciais da Universidade Nove de Julho (UNINOVE). E-mail: leandro_66@ hotmail.com

** Doutora em Ciência: Geografia Humana pela USP. Professora do Programa de Mestrado e Doutorado em Educação da Universidade de Sorocaba (Uniso). E-mail: maria.soares@, prof.uniso.br

${ }^{* * *}$ Doutora em Educação pela Unicamp. Professora do Programa de Mestrado e Doutorado em Educação pela Universidade de Sorocaba (Uniso). E-mail: eliete.nogueira@prof.uniso.br
} 
psychasthenia, to work from de question is a condition of development of contemplation and intellectuality and this becomes the challenge of education.

Keywords: Doubt. Education. Intellectuality. Pedagogical practice. Psychasthenia.

\section{Introdução}

Durante três anos fizemos a mesma pergunta para nossos alunos, estudantes universitários, no primeiro dia de aula e naqueles dias que dão o tom de despedida semestral: qual é sua relação com a tecnologia? Para aqueles cuja pergunta era incompreendida, repetíamos de outras formas: você imagina sua vida sem seu celular? Ou, se você estivesse em um lugar onde não tivesse acesso a nenhum tipo de dispositivo ou, até mesmo informação, como você intui sua sobrevivência? Por meio destas perguntas buscávamos uma rota que pudesse levá-los ao questionamento de sua própria imagem social. Procurávamos os (des)caminhos do inferno. Esquadrinhávamos imagens evocadas que eu sabia com Pais (2001, p. 31), "que, na verdade orientavam os rostos sobre todas as direções (como as máscaras de Picasso), mas que são artificialmente constrangidas a orientarem-se no sentido do que se pretende demonstrar ou explicar”.

As diversas respostas cerravam-se em uma única certeza: a de não haver qualquer tipo de preocupação, pensamento, sentimento e, principalmente, interesse para com as questões levantadas. Assim, percebíamos que no ambiente universitário, na atualidade, existe uma grande preocupação dos alunos para com o mercado, para com os iogurtes, desodorantes. Para com, até mesmo, o desenvolvimento do saber fazer. Difícil era, para nós, compreender, em nossos alunos, algum interesse ou algo que os motivassem ao saber pensar. Qualquer coisa que os conduzissem aos caminhos da atenção entendendo ser a atenção fator essencial para o desenvolvimento do intelecto.

Esta constatação gerou muitas dúvidas sobre o próprio processo educacional. Arrebatou-nos em um oceano formado por angústias. 
Conquista triunfal, porque acreditamos que nem as angústias e, tão pouco, as dúvidas sejam ruins. Ao contrário. Compartilhamos das ideias flusserianas de que "é preciso duvidar. Para começar, é preciso duvidar da dúvida cartesiana porque, mesmo hiperbólica, ela impõe um limite inaceitável" (BERNARDO, 2011, p. 9).

Mas, ficamos à deriva. Nosso horizonte apresentou-se aberto. Sem referências. Momento ideal para qualquer processo criador. Pensar a maneira pela qual nossos alunos interpretam o mundo, segundo e seguindo as lógicas hegemônicas e, por isso mesmo, dominante, nos deixava temerosos. Mas estava consciente de que sem esta condição, não seria possível nos encontrar. Com Deleuze (1996), que pudesse avançar sobre espaços nômades. Que fosse possível construir nossa máquina de guerra.

Nossos alunos acreditavam que o ingresso no mercado de trabalho deveria ser o principal objetivo de uma formação universitária. Este é um objetivo importante, duvidamos, apenas, de sua principalidade. Em contra partida buscávamos mostrar que o desencantamento weberiano, onde "mistérios, maravilhas, prodígios tornaram-se inteligíveis pelo conhecimento científico e regidos pela racionalidade por meio da lógica de mercado" (SOARES, 2001, p. 130) não os deixavam perceber que, nesta lógica, eles também eram mercadorias e, como tal, sucumbidos às leis de oferta e demanda de mercado.

$\mathrm{Na}$ medida em que questões, como as iniciais, eram suscitadas, mesmo quando seguidas de certa dose de ironia, nossos alunos mostravam receio. Uma espécie de medo em desenvolver o próprio pensamento. É como se as questões suscitadas em aula, não permitissem a extração de uma condição psicastênica no qual se encontravam. Desejávamos trazer à tona, a eles, o fato de que "a realidade não é o que pensamos ser real, mas aquela que acreditamos ser real” (PAIS, 2003, p. 35). Mostrar que entre o pensar e sua constituição existe um longo caminho a ser percorrido. Caminho que exigia deles o ingresso, de maneira muito profunda, em suas verdades pré-estabelecidas para, a partir daí, extrair possibilidades de corrupção da lógica dominante que atualmente se apresenta. Entretanto, a condição psicastênica impõe limite, o que, por sua vez, deixou (e ainda deixa) a tarefa proposta mais desafiadora. 


\section{A psicastenia}

A condição psicastênica na qual nossos alunos se encontravam pode ser entendida como o resultado das obsessões e das dúvidas geradas pela percepção incompleta dos sentimentos. Resultado da ausência de atenção e vontade. Do enfraquecimento geral das funções psíquicas. Da internalização de uma anomia que, em principio, é social. Afinal, vivemos um período de céleres transformações tecnocientíficas e de exacerbo informacional que faz com que tenhamos que decidir sobre algo que, antes mesmo da decisão, já passou. Anomia esta que reflete na ausência de tempo, inclusive para delinear qualquer processo reflexivo.

Exauríveis pela psicastenia generalizada que enreda seus cotidianos, estes alunos buscavam, em salas de aulas, modelos operatórios de mercado. Receitas que lhe norteassem em como e quando fazer e que, ao mesmo tempo, os afastassem da premissa básica de qualquer noção ou entendimento do porquê e/ou do para quê fazer. Modelos estes que, para nós, apresentam-se inaceitáveis. Não queríamos transmitir modelos, mas sim, as dúvidas no lugar dos modelos. Dúvidas que temos a consciência de que, por eles, seriam facilmente aceitas, mas dificilmente questionadas. Justamente neste ponto, residia outro problema: a dúvida que não se fazia dúvida e ficava a espreita de um modelo que a realizasse enquanto caminho a ser percorrido. Dúvida que se realizasse como resposta.

Trabalhar com as dúvidas ao invés das certezas também implica na suposição de que o mundo inventado seja melhor do que o mundo recebido e, desta forma, na constatação de que seu olhar sobre o mundo paira sob a medida do fingimento. Fingimento que se relaciona ao próprio pensamento que, preso à mercantilidade, não se realiza, mas faz de conta que sim. Fingimento que se prende nas formas pelas quais os alunos trazem consigo suas representações de mundo. Suas ideias fixas. Suas compulsões. Suas obsessões. Suas realidades inventadas dentro de um plano discursivo cartesiano que os orienta a caminhar com certeza absoluta encaixando-os no padrão socialmente normalizado. Socialmente aceito. Historicamente e hierarquicamente construído. Padrão que exige a docilidade de seus corpos. O controle de suas vidas. E, por isso mesmo, a primazia do processo formativo. 
Incitar a dúvida e extinguir a insegurança sabendo que a primeira leva o sujeito a buscar caminhos. A segunda prende o sujeito entre os caminhos existentes. Quando estes alunos trazem para os espaços escolares suas dúvidas, geralmente elas estão relacionadas à insegurança. Ao medo. A fobia. Suas dúvidas não são instaladas como um estado de espírito polivalente que aliada "à curiosidade, é o berço de toda pesquisa, portanto, de todo o conhecimento sistematizado" (FLUSSER, 2011, p. 21), mas como um sintoma da esquizofrenia. Da neurose. Resultado da vida ordinária que os transformam em sujeitos psicastênicos.

Entre a dúvida-insegurança e a dúvida-polivalente se revela uma dicotomia a ser convergida pela educação formal no papel de seu professor: (re) construção e (re) significação dos sentidos da educação aos alunos que vivem sob a lâmina de uma faca de dois gumes. Percorrem caminhos fronteiriços entre a suposição da realidade e construção do intelecto.

Fronteiriços porque, se por um lado, temos a dúvida como base fundante de toda construção do conhecimento, ou, como diz Flusser, a dúvida "concebida como uma procura por certeza que começa a destruir a certeza autêntica para produzir a certeza inautêntica" (FLUSSER, 2011, p. 22), por outro, temos a dúvida como resultado de um processo de construção induzido e mal resolvido que pode levar, como revela Zorzanelli (2010, p. 423), a

uma série de alterações psicológicas, como sentimentos de incompletude, que abarcaria as operações intelectuais (alteradas pela dificuldade de sustentar a atenção e coordenar ideias), as emoções (transformadas em ruminações, tiques e ansiedade) e a percepção (invadida por sensações de despersonalização e desrealização).

Em outras palavras: a dúvida como fronteira entre o intelecto e a psicastenia.

\section{A dúvida}

Tanto a psicastenia quanto a intelectualidade têm como base a dúvida. A questão que se apresenta refere-se, portanto, às formas pelas 
quais as dúvidas são trabalhadas e, a partir deste trabalho, para qual lugar ela pode nos levar, ou melhor, em qual lugar queremos chegar a partir dela. Por isso mesmo, a dúvida se mostra como cenário, por excelência, tanto da formação do intelecto como a da psicastenia. Por sua vez, constitui-se, desta forma, como dispositivo de formação das subjetividades contemporâneas.

Como nosso objetivo era o de desvelar os tormentos do próprio ato do pensamento, acreditamos ser melhor esclarecer alguns constructos. Para tanto, comecemos com a intelectualidade.

A intelectualidade não pode ser resumida apenas na percepção, na compreensão ou no conhecimento sobre algo. Não se minimiza nas aplicações de conceitos e nem, tampouco, no acompanhamento dos fatos cotidianos que fazem, segundo o senso comum, as pessoas ficarem antenadas sobre tudo o que ocorre no dia a dia nas mais diversas áreas. Seu entendimento vai além, porque, tanto a percepção quanto a compreensão ou, ainda, o conhecimento, envolve uma série de precedentes e sucessões que só são possíveis de ser trabalhados se tivermos clareza do que é e, principalmente, qual é o local da dúvida no intelecto.

A dúvida, segundo Flusser (2011, p. 22) pode ser "concebida como uma procura pela certeza que começa por destruir a certeza autêntica para produzir a certeza inautêntica". Isto implica em dizer que a dúvida pode ser inclusive objeto da própria dúvida e é justamente neste caminho que se inicia o processo de fugacidade do próprio espírito. Isso porque a dúvida da dúvida "é um estado de espírito fugaz. Embora possa ser experimentado, não pode ser mantido" (FLUSSER, 2011, p. 23). Em suma, a dúvida constitui-se, inclusive, na fé autêntica. Na fé de que, de certo, podemos crer somente nas dúvidas sobre os acontecimentos.

Se pensarmos que a dúvida autêntica que nos leva ao intelecto, seu contrário, ou seja, a falsa dúvida, nada mais é do que pura psicastenia. Ainda com Flusser (2011, p. 25), "a dúvida da dúvida se derrama, a partir do intelecto, em direção a todas as demais camadas da mente e ameaça solapar os últimos pontos de senso de realidade". É justamente o respectivo esvaziamento que se firma como papel da universidade. Ainda seguindo a mesma proposição de pensar, posso intuir então que, na medida em que se esvazia o conceito de realidade, se atinge a intelectualidade. Isto deve ocorrer porque o espaço deixado pelo esvaziamento do conceito de 
realidade é preenchido, progressivamente, pelo intelecto, por aquilo que dúvida. Desta forma, a dúvida "invade as demais regiões mentais para articula-las, e as torna, por isso mesmo, duvidosas" (FLUSSER, 2011, p.25). Este entendimento pode ser resumido com Johann Goethe, em sua tragédia Fausto, por intermédio da personagem $O$ bobo, ao afirmar (ou duvidar?) que "só sabemos com exatidão quando sabemos pouco porque na medida em que conhecemos, instala-se a dúvida".

Sendo, então, a dúvida o âmago da intelectualidade, esta última, por sua vez, pode ser entendida conforme Flusser (2011, p. 40), como "o campo onde ocorrem os pensamentos" e, por isso, lócus das subjetividades. Ela não é o que conheço, mas onde se torna possível o conhecer. Ela não é um resultado, mas sim, um princípio de tomada de consciência. Por isso mesmo, é do intelecto que os pensamentos emergirão para, por sua vez, ressignificar a realidade que se apresenta para, a partir dela, esvaziar-se novamente a concepção ora obtida, por meio da dúvida, para posterior ressignificação. Uma espiral que se constrói a partir da dúvida autêntica. Esta é a forma pela qual se concebe a intelectualidade.

Pensando a intelectualidade da maneira exposta acima, percebemos que para dar significado ao pensar, se faz necessário um exercício de "organização lógica dos conceitos" (FLUSSER, 2011, p. 44). Uma organização lógica do próprio pensamento. Exercício este que, a rigor, só se faz possível a partir da concentração. Do desprendimento da atenção para a dúvida.

A atenção para a dúvida é pura contemplação. Faz-se no desenvolvimento da condição de espreita. Isto porque, sem a contemplação, o sujeito não trabalha a concentração e, por isso, não delineia um pensamento mestre que deva conduzir seus pensamentos auxiliares. Com Flusser (2011, p. 36), explicamos melhor esta colocação: para o autor, "o exercício da concentração desvenda, imediata e vivencialmente, a luta entre vontade e intelecto dentro de nossa mente, e pretende fortalecer a vontade contra o intelecto". Isto implica em dizer que "a concentração é a invasão da vontade no território do intelecto: é a vontade que elimina todos os pensamentos, salvo um único" (FLUSSER, 2011, p.36). Tomando com o autor tal afirmativa, é papel da escola o desenvolvimento do exercício da concentração. Da atenção do olhar. Mesmo porque, "o exercício 
da concentração não é um ato bárbaro e indisciplinado. Pelo contrário, é um procedimento bem organizado, de técnica apurada e de êxito pragmaticamente verificável" (FLUSSER, 2011, p. 39). Entretanto, cabe ressaltar que a concentração não exige esforços conceituais, mas sim, a busca pelo campo onde ocorrem os pensamentos, ou seja, a busca pelo intelecto. Esta busca se dá, a priori, pela atenção que se dá a determinada questão. Questão que se formula por meio da dúvida e não pela certeza.

Concentração e atenção são palavras sinônimas (FLUSSER, 2011). Pensemos o trabalho docente por meio do desenvolvimento da atenção, uma vez que, mesmo que interconectadas e/ou expostas, as subjetividades ainda são únicas e são determinantes para o desenvolvimento do olhar, posso afirmar que as dúvidas se apresentam de diversas maneiras aos diversos olhares. Por conta disso, o exercício da atenção se torna tão importante quanto necessário, já que ter um olhar atento para as questões que estão sendo propostas significa em ter como seu o mundo que se apresenta para o outro. Implica em hospedar as angústias do outro em si e, desta maneira, se tornar estrangeiro de si em si mesmo.

A atenção é a própria condição de espreita. Ela sugere que estejamos ao distanciamento certo de algo ou alguém. Não tão próximos que nos faça perder a dimensão do todo, mas também não tão distante que não nos permita enxergar os detalhes. É a busca, como exemplo, do casal apaixonado pela melhor visão do por do sol e, diante deste, a percepção de que naquele momento dia e noite se encontram e se complementam.

Tal percepção só é possível por meio da espreita. Por meio da vigilância sobre o deslocamento da própria atenção. Afinal, é comum estarmos, por exemplo, conversando com alguém e pensando em outra coisa. Este desvio só pode ser controlado por meio do exercício da concentração, pois a atenção é um hábito que se aprende.

Por meio da atenção, estaríamos à espreita do que o futuro nos reserva e, desta forma, conscientes de que as anomias sociais não são fatos isolados dos sujeitos que compõem determinadas sociedades. Ao contrário, são resultantes de um movimento em espiral que envolve a psicastenia e a intelectualidade num grande blefe mercadológico da qual e na qual a educação formal se serve e se orienta. Em decorrência disso, se torna papel da educação hodierna, a realização exercícios que tenham, como resultado, 
o desenvolvimento do olhar atento e da permanente condição de espreita.

Em uma sociedade anômica, cujo excesso provocado pela tecnociência desvia a todo o momento a atenção para qualquer coisa, o exercício da atenção só ganha êxito por meio do desenvolvimento de um olhar atento. Este último, segundo Joseph Esquirol (2009), é a condição básica e estrutural para o desenvolvimento do respeito. Respeito este pelo qual professores em todos os níveis educacionais tanto clamam.

Para Esquirol, refletir sobre a atenção, sobre o olhar atento ou sobre o respeito é refletir sobre exatamente às mesmas coisas. É “olhar de forma desinteressada, sem ceder à vertigem da possessão nem da presunção, e é, sem dúvida o melhor antídoto da auto complacência" (ESQUIROL, 2009, p. 85), da vitimização. Da fantasia sobre a realidade operada pelas maquinarias científicas e pelas leis mercadológicas. Ainda com Esquirol: inimigos da excelência moral.

Vale lembrar com este mesmo autor que "apesar do que possa parecer e tendemos a acreditar, não estamos de modo algum acostumados a olhar a realidade" (ESQUIROL, 2009, p. 86). Mesmo porque, olhá-la atentamente implica em esvaziá-la. Sugere, em decorrência, colocá-la em dúvida. Alude em contradizer as formas pelas quais a sociedade constrói nossas subjetividades. Insinua que a educação formal, como prática de desenvolvimento das potencialidades, não opera de modo eficaz porque apóia às formas secularmente estabelecidas de se exigir a atenção, mas não propõe o desenvolvimento da atenção do olhar ou do olhar para a atenção. Consequência intrínseca do respeito.

\section{A educação formal}

Entendemos a subjetividade como um Eu central cuja manifestação, segundo Flusser (2011, p. 38), pode se dar de duas formas: "o eu que pensa e o eu que quer". Mais uma vez, nos deparamos com ambiguidade que se instala em qualquer humano. Assim, no Eu que pensa, "ocorre uma multiplicidade de pensamentos, e todos eles ocorrem como fios num tear" (FLUSSER, 2011, p. 38). No centro desta multiplicidade de pensamento "corre um fio-mestre fortemente iluminado pela atenção, aparentemente irradiada pelo Eu. Ao redor do fio-mestre, correm fios auxiliares, às vezes 
cruzando, às vezes sustentando o fio mestre" (FLUSSER, 2011, p. 38). Os fios auxiliares são fugazes. Não se prendem. Não possuem sequencia, mas que "estão sempre presentes, porque o cone da atenção pode desviar-se do fio mestre para iluminá-los e torná-los destarte de novos fios mestres" (FLUSSER, 2011, p. 38). Já o Eu que quer, "quer fazer parar o fio-mestre e destruir todos os fios auxiliares". Assim, "O Eu que quer, quer pensar um único pensamento" (FLUSSER, 2011, p. 38).

A maneira pela qual Flusser concebe a formação da subjetividade pode ser, ampliada com Deleuze (1998, p. 35), para quem a subjetividade pode ser entendida como uma dobra: "inflexão das forças do Fora, através da qual se cria um interior. Interior que se encerra dentro de si nada mais que o Fora". Não se trata, portanto, "de uma interioridade fechada sobre si mesma e contraposta à imagem que lhe é exterior" (DELUEUZE, 1998, p. 35). Ela é a relação de si consigo mesmo. É a colcha que se forma no tear de pensamentos compreendido por Flusser.

É na formulação lógica da intelectualidade e da subjetividade que nos deparamos com a tensão dos trabalhos realizados na escola. Ao que parece, pelo menos à primeira vista, as buscas de alunos e os trabalhos docentes têm se resumido à transferência de modelos que são instaurados como verdade. Trabalhos que tendem a forçar a psicastenia em detrimento do abandono da intelectualidade.

Trabalhos que forçam a modelagem objetiva e não as construções subjetivas. Trabalhos que operam com as informações e não com os pensamentos. Informações que se fazem verdades. Verdades cegas. Verdades cruas. Verdades que não aceitam contraposição. Que não se permitem o jogo. Esta é a crucialidade: os recintos escolares estão (re)calcados nas regras e não permitem o próprio jogo. Talvez, este seja o jogo da educação e, por isso, um problema educacional: criar paradoxos de repetição como processo fundamental de aprendizagem. Tecer de maneira mimética, uma rede de passagens entre pensamentos que vão da intelectualidade à psicastenia. Da psicastenia à intelectualidade reproduzindo, desta maneira, a ordem daquilo que se instaura como verdade. Daquilo que se diz ser ciência. Daquilo que pretende ser formal.

Mimesis que representa a própria representação. Que imita do interior para o exterior, porque surge do âmago do desejo de ser fiel a si 
mesmo. Em se tratando da educação formal, imitação que acredita civilizar porque busca tornar mais iguais e mais semelhantes os sujeitos. Igualdade legitimada por sistemas - econômicos, políticos, financeiros - que fazem da educação seu poder de barganha. Educação que contamina corpos ao fazer da biopolítica e do biopoder, dispositivos de subjugação. De corrosão de nossa natureza humana. Educação formal que nos interpela. Que faz do tempo, o ditador de nossos hábitos. De nossos usos, sujeição ao mercado. De nossas ações, moeda de escambo. Da opinião dos outros, nossas opiniões.

Educação formal que, por meio da mimesis, forma e aumenta a massa. Que cria necessidades, operando segundo Tarde (1920, p. 228) com duas grandes categorias: "a credulidade e a docilidade". Categorias que criam e repetem, cada uma a seu modo, paradoxos de repetição do que vai ser, pela ciência, instaurado como padrão e que, pela educação formal, será convergido e aplicado como dispositivo biopolítico no exercício do biopoder foucaultiano.

Uma vez criados os paradoxos de repetição e, por meio deles, da instauração da verdade, alcançamos os mesmos resultados por vários modelos diferentes. Entretanto, poucos são os que se amalgamam no intelecto. A credulidade, por exemplo, envolve a repetição dos modelos já instaurados na tentativa de se obter os mesmos resultados. "Envolve uma adesão totalmente passiva a uma ideia do outro" (TARDE, 1920, p. 228). Submerge da fé de que no outro reside aquilo que desejo e, por isso, sua imitação deve alçar-me às mesmas conquistas. Fé cartesiana. Autêntica. Aparentemente ingênua e inocente. Fé "que caracteriza toda a idade moderna. [...] responsável pelo caráter científico e desesperadamente otimista da idade moderna, pelo seu ceticismo inacabado, ao qual falta das o último passo" (FLUSSER, 2011, p. 23). Fé que ancora os fazeres educacionais que, a cada momento e a todo instante, se desliga dos saberes que ora se constituiu como eixo norteador da educação.

Diferente da credulidade, mas convergente a ela, a imitação pela docilidade se dá pela obediência instaurada como desejo. Como diz Tarde (1920, 229), "um homem enérgico e autoritário exerce sobre as naturezas fracas um poder irresistível: oferecer-lhes o que lhes falta: uma direção". Assim, para estes homens, "a obediência não é um dever, 
mas uma necessidade" (TARDE, 1920, p. 229). Necessidade que a escola tenta sedimentar como meio de normatização e controle das maneiras pelas quais se firmam os laços sociais. Autoridade em decadência corrompida pelo desprezo.

Tarde, no início do século XIX, já alertava para o fato de que a obediência e a credulidade são irmãs e andam juntas. "As pessoas obedecem pela mesma razão que acreditam; e, do mesmo modo que a sua fé é a irradiação da de um apóstolo, a sua atividade é senão a propagação da vontade de um mestre" (TARDE, 1920, p. 229). A dúvida que levantamos relaciona-se ao mestre que, atualmente, seguimos. O consumo? A moda? O mercado? O espetáculo? O conhecimento? Ou, simplesmente, a mim mesmo? Seja qual for a resposta, a educação formal perde seu poder legitimador do processo formativo pessoal e, por isso mesmo, suas ações, desde o final da idade média e início do período moderno, tornam-se repetição de processos cuja sociedade já se saturou. Remakes de filmes a muito já vistos. Tentativas de perpetuação e permanência daquilo que já não emana mais vigor, pois a sociedade atual se solidifica nos mecanismos de controle e escavam, como máquinas de guerra, as macroestruturas legitimadoras de uma autoridade exercida sobre os corpos. Desta maneira, a educação formal apresenta-se tão superficial quanto errante.

Dada sua intenção formativa, a educação formal acaba operando no hiato entre a psicastenia e a dúvida do intelecto. Em vão. Não consegue ligar as dúvidas e, por isso, não liga os respectivos campos - o da intelectualidade e o da psicastenia promovendo, por sua vez, a incompletude na/da formação dos sujeitos. É como se ela não conseguisse realizar a passagem entre o real e o imaginado. É como se Tânatos não deixasse o reino dos vivos e, também, não alcançasse o reino dos mortos. A educação formal sofre à deriva no sortilégio da própria sorte.

$\mathrm{Na}$ tentativa de alterar as percepções do sujeito sobre o real, a educação formal tenta desdobrar-se. Reconstruir-se. Superar-se. Não gera vontade. Não reúne desejos. Sob esta perspectiva ela não se assemelha a Tânatos. Aproxima-se de Hades, cujas trevas lhe foram impostas. Mesmo que à deriva, porque mata as pessoas que nela acreditam. Situação melhor entendida com Fernando Pessoa (2006) em seu poema Nada fica de nada já que, na atualidade, "Nada fica de nada", pois "Nada somos". Assim, só nos 
resta "Um pouco ao sol e ao ar nos atrasamos", porque "Da irrespirável treva que nos pese" e na tentativa de viver "Da humilde terra imposta", a educação formal, hoje, corrobora por nos transformar em "Cadáveres adiados que procriam".

A educação formal assim se apresenta porque em uma sociedade autolimpante, como referenciada por Almeida (2010, p. 51): "aos olhos dos alunos, o discurso do professor constitui-se um blefe, fala de coisas distantes de sua vivência cotidiana, de saberes descolados das suas referências, não representam mais os modelos com os quais se identificam". É um blefe porque não consegue fugir do abismo no qual se encontra. Enquanto blefe, ela transforma seus sujeitos em grandes operadores do nada sobre o nenhum. Seu principal objetivo se estabelece na reorientação de seus hábitos. De suas práticas. Ela não distingue a aparência do ser, pois sua preocupação esta em "eleger, como blefe, falsas verdades, e de guardar, para poucos, as que poderiam ser boas" (KODO, 2001, p. 23).

O discurso do professor, enquanto blefe, gera uma das dificuldades em se trabalhar com as dúvidas ao invés das certezas. Esta dificuldade está justamente no fato de que, sem certezas, perdemos os ideais de representação. Deixamos de "acreditar que as histórias que ouvimos de nossos professores e pais ainda valem para alguma coisa" (KODO, 2001, p. 23), correndo, ainda, o risco de despertarmos nos alunos dúvidas sobre suas estruturas. Sobre as hierarquias. Corremos o risco de que eles percebam que as regras que aprenderam "podem ser reajustadas a qualquer situação, conforme aparecem ou como são jogadas" (KODO, 2001, p. 38).

A educação formal, sem se preocupar com a psicastenia ou com o intelecto, corrobora com as insuficiências psicológicas de seus sujeitos. (Re)afirma uma espécie de "anomia social". Faz da intuição o ponto de partida para o entendimento de qualquer ação que não esteja ligada ao seu estudo. Busca moldar o sujeito para que este se adapte ao seu modelo. Tarefa arriscada já que seu principal fenômeno a ser estudado é justamente o sujeito que liga todos os outros fenômenos que ocorrem em determinada sociedade: o homem. $\mathrm{O}$ que pode parecer, à primeira vista, um ato inocente e banal ou, até mesmo, o cumprimento de algumas normas institucionalizadas, pode esconder, para os alunos, uma grande emboscada: Sob o álibi de que a educação formal irá ajudá-lo a ingressar em um mundo 
melhor, a educação acaba, por sua vez, por reafirmar "uma definição política que tem a ver com os objetivos que uma sociedade determina para si" (SANTOS, 1996). Ela acaba por alicerçar a insegurança quando opta por afogá-lo no sentimento de incompetência criado neste aluno quando, a princípio, sabemos se tratar de uma anomia social provocada pela própria educação.

A anomia social, neste texto, deve ser entendida a partir da conceituação de Durkheim (2002), para quem as relações sociais em torno do trabalho superam o desenvolvimento individual do sujeito. Partindo deste preceito, podemos compreender que a educação formal, ao buscar "desenvolver habilidades e potencialidades dos sujeitos" dentro de uma sociedade que se regula pelo mercado de trabalho, acaba por promover a desregulação desta sociedade, já que força os indivíduos a se encaixarem em um modelo já estabelecido. Tenta extrair dos sujeitos a docilidade. Tenta domesticá-los. Chega, muitas vezes, a querer se colocar como dogma e direcionar, desta forma, seus participantes pela fé. O entrave se encontra no fato de que o mercado nos seda. Seduz. Hipnotiza. Em decorrência, a preocupação para com o mercado e a busca do desenvolvimento econômico em detrimento do desenvolvimento moral e da busca pela integridade pessoal, gera esta sociedade direcionada pelo brilho. De efemeridade latente. Doente.

A educação formal busca (sobre) viver numa sociedade anômica formada por sujeitos psicastênicos. Pessoas cujo desenvolvimento intelectual não ocorre porque a educação formal, uma das poucas possibilidades de se trabalhar com a formação do indivíduo, está corroída por forças que operam dentro das certezas modernas. Nas ações educacionais atuais não existem espaços para as dúvidas. "Falta vida na sala de aula. Falta poesia, falta imagem, falta diálogo, falta o Ser, falta a existência" (SANTOS, 2005, p. 42). Falta vida porque na sociedade a qual esta educação serve, não existe tempo para as dúvidas. Sem espaço e sem tempo, inexiste a possibilidade de contemplação e, por isso mesmo, a estes indivíduos, o fio-mestre ao qual se referiu Flusser, perde o cone luminoso da atenção.

É como se vivêssemos cobertos por uma teia tecida com pensamentos auxiliares. Dispersos. Errantes. Teia que não prende porque seus fios são frouxos. Desorientados. Assim, encontramos os sujeitos 
da educação: pessoas que não aprenderam a contemplar simplesmente porque não tiveram tempo e nem espaço para isto e, por isso, buscam o pertencimento por meio do que lhe é prontamente dado e instantaneamente abandonado. Esquecido.

Desculpas para a (des)regulação funcional da educação não falta. Podemos começar pelos alunos que, a priori, recebem dos discursos hierarquicamente instituídos a culpa pela indisciplina que geram. Pela desatenção. Pelo desalento ao currículo escolar. Passamos, posteriormente, aos professores que, ainda mantendo a mesma hierarquia, não desempenham bem seus papéis em sala de aula. Profissionais que, para muitos, devem ser imbuídos do "dom" do ensinare da paciência quase santa de Cristo. Seguindo a hierarquia hegemonicamente instituída, chegamos aos coordenadores que não coordenam ou que não possuem uma "pedagogia adequada". Os diretores que não dirigem e exercem o autoritarismo ao invés da autoridade e, desta forma, sufocam-se pelas próprias conspirações de seu ofício. Dirigentes e secretários de ensino empossados como gratificação eleitoral, cuja competência é tão questionável quanto os engenhosos planos que os conduziram ao cargo. Ao passarmos pelas câmaras, pelo senado, pela presidência e, por todas as instâncias executivas e legislativas, encontramos possíveis "culpados" pela degeneração da educação formal. Mas não encontramos a causa e esquecemos de que quase todos nós passamos pelo mesmo processo e, por isso, somos orientados a buscar a causa certa e não a buscar a dúvida provável.

A tensão entre o tempo educacional e o tempo social atual que convergem na educação formal, pode ser explicada, ou, pelo menos, intuída: no período moderno a educação formal funcionou como processo de instituição e normatização social. Hoje, sofre as consequências de ter suas fantasias desmentidas pela dura realidade que se apresenta. Não percebe que tradicionalismo não é sinônimo de velharia e que o movimento tecnocientífico, político e econômico atual formam verdadeiros furacões com as quais ela se propõe a lutar. Assim, acredita que o desenvolvimento de potencialidades seja a memorização de passos básicos para a operacionalização de uma máquina. Permite com que o mercado, ao reorientar o processo educacional, reordene, por seu turno, a vida dos indivíduos que, a esse processo, se submete. 


\section{Conclusão}

Concluímos que, na atualidade, frente à psicastenia e a intelectualidade, a educação formal deve ser crepuscular. O crepuscular, segundo Santos (2005, p. 17), "pode ser entendido como aquele momento específico no final da tarde, no trânsito entre o dia e a noite, quando todos os insetos se agitam em torno de alimentos". O crepuscular é "um momento difuso por excelência, limítrofe, liminal, que tem como motivação básica de seus seres a busca pela alimentação" (SANTOS, 2005, p. 17). É o momento da interlocução entre os animais que caçam durante o dia e estão buscando seu recolhimento e os animais que caçam durante a noite e estão saindo para a captura. É o momento da síntese resultante do homem diurno e o homem noturno bachelardiano. É o momento da espreita por excelência.

Ao transformar os dizeres de Flusser (2011), Esquirol (2006) e Santos (2005) em um tecido orgânico, percebemos, então, que o respeito está intimamente relacionado ao alcance da intelectualidade que, por sua vez, só se faz possível por meio da espreita ou da atenção para com os objetivos propostos. Todavia, é importante lembrar que não me refiro à intelectualidade como sinônimo de erudição ou saber fazer científico. Apesar de a universidade auxiliar no exercício do pensar sistematizado, o alcance do intelecto pode se dar em qualquer meio. Em qualquer cena. Em qualquer momento do cotidiano. Para tanto, como explicitado, basta à atenção aos fatos que se fazem como objeto do pensar.

A atenção, como nos lembra Esquirol, "não é um movimento frequente, mas raro" (2008, p. 11). Exige o esforço da concentração ao qual Flusser (2011) se refere. Não é um movimento "apenas para resgatar ao outro ou o outro, mas também a si mesmo" (ESQUIROL, 2011, p. 11). Por isso mesmo, a atenção, quando pensada como mecanismo de demarcação da intelectualidade denota, também, o respeito a si mesmo. Este último é resultado de uma ação "das imagens noturnas para o herói diurno em vigília e combate, e imagens diurnas para o místico recolhido em seu abrigo" (SANTOS, 2005, p. 42). O respeito "incita a busca de Si mesmo. Um diálogo profundo entre o conhecimento e a busca de experiência de uma verdade - particular, singular e de uma realização" (SANTOS, 2005, p. 42). 
Este diálogo de Si e para Si resulta do exercício mental da atenção. Só se torna possível se pensarmos, com Flusser (2011), a dúvida como elemento fundante da busca. Só se torna possível se trilharmos, com Santos (2005, p. 47), o caminho do dia para a noite e o da noite para o dia, "modificando o nosso olhar sobre as coisas e, modificando o olhar, amanhar a própria mão, [...] descobrindo que o diálogo é a condição primeira do conhecimento: descobrir e descobrir-se no outro".

Só prestamos atenção quando queremos algo. Um retorno. Uma resposta. Um entendimento. Entretanto, em uma sociedade cuja marca é o excesso, principalmente informacional, se faz preciso refletir a fundo o que merece atenção, "o que "merece" respeito, pois por infelicidade é demasiado frequente que o que deve ser respeitado não o seja, e que o que é efetivamente respeitado não deveria sê-lo" (ESQUIROL, 2011, p. 16). Ao nos interessarmos pelas certezas ao invés das dúvidas, acabamos por cooptar com a indiferença e o consumo que caracterizam, junto ao excesso, alguns sintomas da anomia de nossa sociedade. Tal cooptação contribui para os desvios da atenção e, consequentemente, do respeito. Isto ocorre porque é "somente quando alguém compreende onde está e quais são as características mais relevantes de seu contexto, torna-se capaz de atuar, de decidir e, definitivamente, de viver e conviver melhor" (ESQUIROL, 2011, p. 23). Compreensão esta suprimida por algumas universidades brasileiras por meio de seus processos e procedimentos técnicos direcionados para as atividades mercantis.

Aqui, um jogo lógico para melhor entendimento do que se explicita: sem dúvidas, sem atenção. Sem atenção, sem respeito. Sem respeito, sem interação. Sem interação, a informação não (in)forma. Sem a formação, as atividades docentes morrem em utopias.

Ao questionar o papel da tecnologia no dia a dia dos alunos busco também a percepção, por parte deles, de como as tecnologias têm se tornado um poderoso sistema. Não faz muito sentido dialogar sobre as facilidades de um celular ou de um cartão de crédito, mas sim, como este potente sistema tecnológico os envolvem em uma poderosa rede econômica, política e informacional. Entretanto, suas condições psicastênicas têm retornado "um imediatismo tão natural que resulta irrefletido, sem distância" (ESQUIROL, 2011, p. 33). Isto porque algumas universidades, atualmente, 
assim trabalham: na busca de melhores resultados do saber fazer por meio das políticas de desenvolvimento de habilidades e competências que são, por sua vez, avaliadas (?) por questões práticas que exigem respostas objetivas em detrimento da busca da compreensão e, assim, do exercício do deslocamento da atenção e da concentração na dúvida. É como se as universidades, hoje, dessem o peixe ao invés de ensinar a pescar.

\section{Referências}

ALMEIDA, Rogerio M. Educação contemporânea: a sociedade autolimpante, o sujeito obsoleto e a aposta na escolha, Rio Claro, Educação: teoria e prática, v. 20, n. 34, jan.- jun. 2010, p. 47-64.

BERNARDO, Gustavo. Apresentação. In: FLUSSER, Vilém. A dúvida. São Paulo: Annablume, 2011.

DELEUZE, Gilles. A lógica dos sentidos (1969). São Paulo: Perspectiva, 1998.

. Conversações. Rio de Janeiro: 34, 1996.

DURKHEIM, Émile. As regras do método sociológico. São Paulo: Editora Martin Claret, 2002.

ESQUIROL, Joseph M. O respeito ou o olhar atento: uma ética para a era da ciência e da tecnologia. Belo Horizonte: Autêntica, 2009.

FLUSSER, Vilém. Do Espelho. In: FLUSSER, Vilém. Ficções filosóficas. São Paulo: Editora da Universidade de São Paulo, 1998, p. 67-71. . A história do diabo. São Paulo: Annablume, 2008a, 3 ed.

. O mundo codificado: por uma filosofia do design e da comunicação.

São Paulo: Cosac Naif, 2008b.

. O universo das imagens técnicas: elogio da superficialidade. São

Paulo: Annablume, 2008c. . A dúvida. São Paulo: Annablume, 2011.

FOUCAULT, Michael. A ordem do discurso. São Paulo: Loyola, 2009.

KODO, Louis L. Blefe: o gozo pós-moderno. São Paulo: Zouk, 2001.

PAIS, Jose Machado. Vida cotidiana: enigmas e revelações. São Paulo: 
Cortez, 2003.

SANTOS, Milton. A natureza do espaço. São Paulo: Hucitec, 1996.

. Técnica, espaço, tempo. 5. ed., São Paulo: Edusp, 2008.

SANTOS, Marcos Ferreira. Crepusculário. São Paulo: Zouk, 2005, 2 ed.

SOARES, Maria Lucia de Amorim. Girassóis ou Heliantos: maneiras criativas para conhecer o geográfico. Sorocaba: LINC, 2001.

TARDE, Gabriel. As leis da imitação. Porto: Editora Rés, [1920].

VILLAÇA, Nilza. Mixologias: Comunicação e o consumo da cultura. São Paulo: Estação das Letras, 2010.

ZORZANELLI, Rafaela Teixeira. Psicastenia. Hist. cienc. saudeManguinhos, Rio de Janeiro, 2011. Disponível em: <http://www. scielo.br/scielo.php?script $=$ sci_arttext\&pid=S0104-597020100006000 09\&lng=pt\&nrm=iso $>$. Acesso em: 07 Ago. 2011.

Data de registro:26/01/2012

Data de aceite: $15 / 02 / 2013$ 